\title{
Editorial: Phosphoinositides and their phosphatases: Linking electrical and chemical signals in biological processes
}

\author{
Susy C. Kohout ${ }^{1 *}$ and Carlos A. Villalba-Galea ${ }^{2 *}$ \\ ${ }^{1}$ Department of Cell Biology and Neuroscience, Montana State University, Bozeman, MT, USA, ${ }^{2}$ Department of Physiology \\ and Biophysics, Virginia Commonwealth University School of Medicine, Richmond, VA, USA
}

Keywords: voltage-sensing phosphatase, membrane potential, cell signaling, phosphatidylinositols, pten

\section{OPEN ACCESS}

Edited by:

Jean-Yves Le Guennec, Université de Montpellier, France

Reviewed by: Sébastien Roger University of Tours, France

${ }^{*}$ Correspondence:

Susy C. Kohout, skohout@montana.edu; Carlos A. Villalba-Galea,

cavillalbaga@vcu.edu

Specialty section:

This article was submitted to Pharmacology of lon Channels and

Channelopathies,

a section of the journal

Frontiers in Pharmacology

Received: 11 June 2015

Accepted: 26 June 2015

Published: 08 July 2015

Citation:

Kohout SC and Villalba-Galea CA (2015) Editorial: Phosphoinositides and their phosphatases: Linking electrical and chemical signals in biological processes.

Front. Pharmacol. 6:142. doi: 10.3389/fphar.2015.00142
The voltage-sensing phosphatase (VSP) has changed the way we think about both cellular electrical activity and PIPs (phosphatidylinositol phosphates). Originally discovered in 1999 (Chen et al., 1999), these proteins were not recognized as electrically-controlled enzymes until 2005 (Murata et al., 2005). They constitute the first, and so far the only, example of an enzyme linking electrical signals at the plasma membrane to the catalysis of PIPs (Murata et al., 2005), a ubiquitous family of intracellular signaling molecules (Di Paolo and De Camilli, 2006; Balla, 2013). Before the discovery of VSP, there were no known direct links between the two. Textbook examples would represent this connection with arrows, alluding to indirect or "yet-to-be-defined" signaling pathways. Now we know that VSP serves as a direct connection between the electrical nature of the cell and PIPs, lipid second messengers that are critical for cell survival. However, many questions remain unanswered regarding VSP and its electrical regulation of cellular processes.

With the discovery of VSP, the membrane potential must now be considered when studying PIP regulators. PIPs are involved in almost all aspects of cell physiology from survival, proliferation, and migration to pre-programed cell death (Di Paolo and De Camilli, 2006; Logothetis et al., 2010; Koch and Holt, 2012; Balla, 2013). For example, PIP concentrations are actively polarized in migrating cells with phosphatidylinositol-3,4,5-trisphosphate $\left(\mathrm{PI}(3,4,5) \mathrm{P}_{3}\right)$ on the leading edge and phosphatidylinositol-4,5-bisphosphate $\left(\mathrm{PI}(4,5) \mathrm{P}_{2}\right)$ on the lagging edge (Leslie et al., 2008). These gradients in the concentration of PIPs are necessary for activation of Rac and Rho leading to cell motion. PIPs are also crucial for cell growth: $\mathrm{PI}(3,4,5) \mathrm{P}_{3}$ activates the mTor cascade leading to increased protein, membrane, and nucleic acid production (Dibble and Manning, 2013). Many human diseases have been associated with altered homeostasis of PIPs, including cancer, developmental disorders, and Alzheimer's disease (Simpson and Parsons, 2001; McCrea and De Camilli, 2009; Hakim et al., 2012). Though the physiological relevance of VSP is not yet defined, it is still crucial to human health to understand how PIPs are regulated and that now includes VSP.

All cells have an asymmetric composition of ions across their plasma membrane, which, combined with selective permeabilities for these ions, results in a difference in the electrical potential across their plasma membrane. This difference, called the membrane potential, constitutes a form of cell signaling and a source of energy, both driving many biological processes. This electrical potential difference powers neuronal excitability as well as more general processes like proliferation, migration, and development (Levin, 2007; Sundelacruz et al., 2009; Yao et al., 2011). Regulation by the membrane potential has long been the sole purview of ion channels and transporters and that has influenced what questions are asked regarding the changing potential. With our new knowledge of VSP, the changing membrane potential can directly signal the cell by modulating mTor and cell growth pathways, leading to abnormal growth or the M-current in sympathetic ganglion, leading to hyperexcitability. 
The articles in this Special Topic highlight several features of VSP including its unique activation, its similarities to other enzymes and its use as a versatile tool to study other proteins. In the review article by Hobiger and Friedrich (2015, p. 20), the authors compare the structural similarities and differences between the broader family of protein tyrosine phosphatases and one of its newest members, VSP. They suggest a catalytic mechanism based on this comparison. Castle et al. (2015, p. 63) investigate the activation mechanism of VSP by probing the C2 domain, the C-terminal domain of VSP that has been largely unrecognized before the recent crystal structures showed a direct contribution of the $\mathrm{C} 2$ residue $\mathrm{Y} 522$ into the active site. The work by Mavrantoni et al. (2015, p. 68) explores the techniques that are used to test VSP and address some of their limitations including the need for expensive electrophysiology equipment as well as the limitations of using channels as functional reporters. They take their methods and apply them to a chimera between the Ciona intestinalis VSP and human PTEN and show how the chimera allows for the investigation of PTEN using standard techniques but with the advantage of regulated activation, voltage.

Beyond the molecular mechanism underlying VSP activity, Mori et al. (2015, p. 22) review the use of VSP as a relatively simple tool for manipulating $\mathrm{PI}(4,5) \mathrm{P}_{2}$ concentrations in cells. They have used VSP to study the $\mathrm{PI}(4,5) \mathrm{P}_{2}$ regulation of transient receptor potential canonical channels involved in receptoroperated calcium currents. Along the same lines, Rjasanow

\section{References}

Balla, T. (2013). Phosphoinositides: tiny lipids with giant impact on cell regulation. Physiol. Rev. 93, 1019-1137. doi: 10.1152/physrev.00028.2012

Castle, P. M., Zolman, K. D., and Kohout, S. C. (2015). Voltage-sensing phosphatase modulation by a C2 domain. Front. Pharmacol. 6:63. doi: 10.3389/fphar.2015.00063

Chen, H., Rossier, C., Morris, M. A., Scott, H. S., Gos, A., Bairoch, A., et al. (1999). A testis-specific gene, TPTE, encodes a putative transmembrane tyrosine phosphatase and maps to the pericentromeric region of human chromosomes 21 and 13, and to chromosomes 15, 22, and Y. Hum. Genet. 105, 399-409. doi: $10.1007 / \mathrm{s} 004390051122$

Dibble, C. C., and Manning, B. D. (2013). Signal integration by mTORC1 coordinates nutrient input with biosynthetic output. Nat. Cell Biol. 15, 555-564. doi: $10.1038 / \mathrm{ncb} 2763$

Di Paolo, G., and De Camilli, P. (2006). Phosphoinositides in cell regulation and membrane dynamics. Nature 443, 651-657. doi: 10.1038/nature05185

Hakim, S., Bertucci, M. C., Conduit, S. E., Vuong, D. L., and Mitchell, C. A. (2012). Inositol polyphosphate phosphatases in human disease. Curr. Top. Microbiol. Immunol. 362, 247-314. doi: 10.1007/978-94-007-5025-8_12

Hobiger, K., and Friedrich, T. (2015). Voltage sensitive phosphatases: emerging kinship to protein tyrosine phosphatases from structure-function research. Front. Pharmacol. 6:20. doi: 10.3389/fphar.2015.00020

Koch, M., and Holt, M. (2012). Coupling exo- and endocytosis: an essential role for $\mathrm{PIP}_{2}$ at the synapse. Biochim. Biophys. Acta 1821, 1114-1132. doi: 10.1016/j.bbalip.2012.02.008

Leslie, N. R., Batty, I. H., Maccario, H., Davidson, L., and Downes, C. P. (2008). Understanding PTEN regulation: PIP2, polarity and protein stability. Oncogene 27, 5464-5476. doi: 10.1038/onc.2008.243

Levin, M. (2007). Large-scale biophysics: ion flows and regeneration. Trends Cell Biol. 17, 261-270. doi: 10.1016/j.tcb.2007.04.007

Logothetis, D. E., Petrou, V. I., Adney, S. K., and Mahajan, R. (2010). Channelopathies linked to plasma membrane phosphoinositides. Pflugers Arch. 460, 321-341. doi: 10.1007/s00424-010-0828-y

Mavrantoni, A., Thallmair, V., Leitner, M. G., Schreiber, D. N., Oliver, D., and Halaszovich, C. R. (2015). A method to control phosphoinositides and to et al. (2015, p. 127) use VSP as a tool that gives them precise control over the $\mathrm{PI}(4,5) \mathrm{P}_{2}$ concentrations in the membrane. These authors compared the relative PIP affinities between several ion channels. They also point out an important limitation that the channels must already have a known specificity for a particular PIP because VSP does not destroy PIPs in contrast to phospholipase C; instead, it generates multiple PIPs. All together, these articles underscore the features of VSP and expand our understanding of its function and utility.

Though VSP remains relatively unknown to many, this nascent field has shown fast initial growth. The unique nature of these enzymes has inspired many to investigate their properties as well as take advantage of them. Many questions remain unanswered regarding VSP such as how the voltage sensor couples to the enzyme and whether the phosphatase domain is brought to the membrane for activation or whether a conformational change within the active site determines activation. We look forward to the studies that will address these and the many other questions that persist in this exciting field.

\section{Acknowledgments}

This work was supported by start-up funds from the Montana State University Vice President for Research, Creativity and Technology Transfer and NSF EPSCoR (EPS-1101342) to SK and CTSA - KL2TR000057 to CV.

analyze PTEN function in living cells using voltage sensitive phosphatases. Front. Pharmacol. 6:68. doi: 10.3389/fphar.2015.00068

McCrea, H. J., and De Camilli, P. (2009). Mutations in phosphoinositide metabolizing enzymes and human disease. Physiology 24, 8-16. doi: 10.1152/physiol.00035.2008

Mori, M. X., Itsuki, K., Hase, H., Sawamura, S., Kurokawa, T., Mori, Y., et al. (2015). Dynamics of receptor-operated $\mathrm{Ca}^{2+}$ currents through TRPC channels controlled via the PI(4,5)P2-PLC signaling pathway. Front. Pharmacol. 6:22. doi: 10.3389/fphar.2015.00022

Murata, Y., Iwasaki, H., Sasaki, M., Inaba, K., and Okamura, Y. (2005). Phosphoinositide phosphatase activity coupled to an intrinsic voltage sensor. Nature 435, 1239-1243. doi: 10.1038/nature03650

Rjasanow, A., Leitner, M. G., Thallmair, V., Halaszovich, C. R., and Oliver, D. (2015). Ion channel regulation by phosphoinositides analyzed with VSPs-PI(4,5) $\mathrm{P}_{2}$ affinity, phosphoinositide selectivity, and $\mathrm{PI}(4,5) \mathrm{P}_{2}$ pool accessibility. Front. Pharmacol. 6:127. doi: 10.3389/fphar.2015. 00127

Simpson, L., and Parsons, R. (2001). PTEN: life as a tumor suppressor. Exp. Cell Res. 264, 29-41. doi: 10.1006/excr.2000.5130

Sundelacruz, S., Levin, M., and Kaplan, D. L. (2009). Role of membrane potential in the regulation of cell proliferation and differentiation. Stem Cell Rev. 5, 231-246. doi: 10.1007/s12015-009-9080-2

Yao, L., Pandit, A., Yao, S., and McCaig, C. D. (2011). Electric field-guided neuron migration: a novel approach in neurogenesis. Tissue Eng. Part B Rev. 17, 143-153. doi: 10.1089/ten.teb.2010.0561

Conflict of Interest Statement: The authors declare that the research was conducted in the absence of any commercial or financial relationships that could be construed as a potential conflict of interest.

Copyright (C) 2015 Kohout and Villalba-Galea. This is an open-access article distributed under the terms of the Creative Commons Attribution License (CC BY). The use, distribution or reproduction in other forums is permitted, provided the original author(s) or licensor are credited and that the original publication in this journal is cited, in accordance with accepted academic practice. No use, distribution or reproduction is permitted which does not comply with these terms. 